\title{
Thermal behavior and polymorphism in medium-high temperature range of the sulfur containing amino acids L-cysteine and L-cystine
}

\author{
Concepción Foces-Foces • María Victoria Roux • \\ Rafael Notario • Marta Segura
}

ESTAC2010 Conference Special Issue

(C) The Author(s) 2011. This article is published with open access at Springerlink.com

\begin{abstract}
A thermophysical study of the sulfur containing amino acids L-cysteine and L-cystine has been carried out by differential scanning calorimetry (DSC). Heat capacities of both compounds were measured in the temperature interval from $T=268 \mathrm{~K}$ to near their respective melting temperatures. DSC and variable temperature powder X-ray diffraction analysis (PXRD) gave evidence for a solid-solid phase transition close to the melting point only in the L-cysteine sample. DSC experiments show that this solidsolid transition is not reversible in the temperature interval $T=235-485 \mathrm{~K}$ and presents a behavior depending on heating temperature, time, and rate. This behavior is also supported by variable-temperature PXRD. The patterns for the commercial samples, at room temperature, are consistent with those simulated for the orthorhombic and hexagonal polymorphic forms from the single-crystal X-ray analysis.
\end{abstract}

Keywords L-Cysteine - L-Cystine - Heat capacities · Phase transition - Differential scanning calorimetry · Powder X-ray diffraction

\section{Introduction}

The aim of this work is to study the thermal behavior in the medium-high temperature range of the sulfur containing amino acid L-cysteine and its corresponding dimer

C. Foces-Foces $\cdot$ M. V. Roux $(\bowtie) \cdot R$. Notario Institute of Physical Chemistry "Rocasolano", CSIC,

Serrano 119, 28006 Madrid, Spain

e-mail: victoriaroux@iqfr.csic.es

M. Segura

PerkinElmer España S.L., Ronda de Poniente 19, 28760 Tres Cantos Madrid, Spain
L-cystine, which is composed of two L-cysteine units joined by a disulfide bond (Fig. 1).

Both molecules are naturally present in proteins and polypeptides. Cysteine is the only monomeric amino acid with a reactive sulfur moiety, the side chain being a thiol group. The strong nucleophilicity of cysteine makes it a key component of the active site of many enzymes [1-3]. The thiol is susceptible to oxidization to give the disulfide derivative cystine, which serves an important structural role in many proteins. Indeed, the prototype of a protein disulfide bond is cystine.

The thiol-disulfide interchange reaction is important to a number of subjects in biochemistry [3-5] including the renaturing of proteins and stabilization of proteins in solution. Thus, thermodynamic data regarding the relative energetics of the thiol and disulfide functional groups is essential for the understanding of the driving force and mechanism of biochemical processes. In industry, disulfide bonds are the crosslinking groups that result from the vulcanization of rubber.

Temperature-induced changes in crystalline amino acids are of interest for their properties [6] and because they reveal the intrinsic motions of these structural fragments and their contribution to the dynamic properties of proteins [7].

Several polymorphic forms have been reported for both compounds. L-Cysteine crystallizes in the monoclinic and orthorhombic forms and has been structurally characterized by X-ray [8-10] and neutron [11] diffraction methods at ambient and low temperatures [12-14] as well as at ambient and higher pressures [15]. Phase transitions have been detected when lowering the temperature (ca. $70 \mathrm{~K}$ ) [14] and also when increasing pressures up to $4.2 \mathrm{GPa}$ and decreasing to $1.7 \mathrm{GPa}$ [15]. L-Cystine crystallizes in the tetragonal and hexagonal forms and has also been studied at ambient [16, 17] and at low temperature [18] and at high 
Fig. 1 Schematic formulae of L-cysteine 1 and L-cystine 2<smiles>NC(CS)C(=O)O</smiles>

1<smiles>NC(CSSCC(N)C(=O)O)C(=O)O</smiles>

2 pressures [19]; however, no solid-solid phase transition has been detected.

Earlier heat capacities of samples of L-cysteine and L-cystine were measured in the temperature range $T=85-298 \mathrm{~K}$ and neither any hint of a phase transition nor a weak anomaly were reported in both compounds [20, 21]. Recently an extended phase transition in orthorhombic crystalline L-cysteine near $T=70 \mathrm{~K}$ was reported [22].

For several years, we have been involved in the experimental determination of the enthalpies of fusion, heat capacities and the study of polymorphism of pure organic molecules [23-30]. Very recently we have carried out [31] a thermochemical study of L-cysteine and L-cystine reporting their molar enthalpies of formation. In the present work we report the thermal behavior of both compounds studied by differential scanning calorimetry (DSC) and variable temperature powder X-ray diffraction (PXRD) in the temperature interval from $T=268 \mathrm{~K}$ to near their respective melting temperatures.

\section{Experimental section}

Material and purity control

L-Cysteine, [CAS 52-90-4] and L-cystine [CAS 56-89-3] were commercially available from Fluka (both BioUltra $\geq 99.5 \%$ ). The samples were carefully dried under vacuum and no further purification was performed.

The standards used for DSC calibration were hexafluorobenzene, $99.9 \%$ purity, supplied by Aldrich; benzoic acid, NIST standard reference sample 39j; high-purity indium (mass fraction >0.99999), tin and synthetic sapphire, supplied by Perkin Elmer.

X-ray diffraction studies

Powder X-ray diffraction analysis was used to identify the polymorphic forms of the commercial samples and to analyze the thermal behavior at medium-high temperatures. The powder patterns for both compounds were collected on a PANalytical XPert'PRO MPD powder diffractometer $(\mathrm{Cu} \mathrm{K} \alpha)$ fitted with an Anton Paar HTK 1200 variable temperature oven with an alumina sample cup recovered with platinum film to avoid any pressure on the sample.

Structural data for the polymorphic forms of L-cysteine and L-cystine was obtained from the Cambridge Structural Database [32] (CSD refcodes: LCYSTN to LCYSTN36 for L-cysteine [8-15] and LCYSTI10 to LCYSTI13 for L-cystine [16-19]). The PLATON [33] (as incorporated into the WinGX package [34]) and XPowder [35] software were used to prepare material for visualization and analysis.
Fig. 2 Curves for a L-cysteine and $\mathbf{b}$ L-cystine
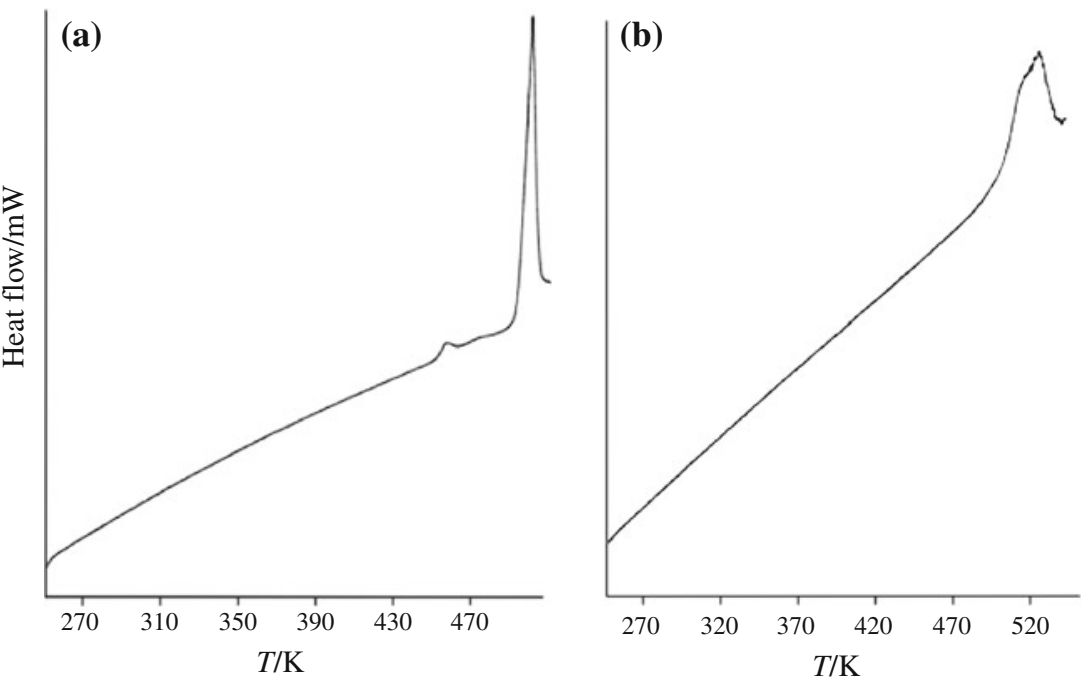
Procedure for calorimetric measurements

The behavior of the samples as a function of temperature was studied by DSC. A DSC Pyris 1 instrument from Perkin Elmer equipped with an intra-cooling unit was used to study the fusion process and the possible existence of phase transitions in the solid samples at temperatures above $T=260 \mathrm{~K}$ to their respective temperatures of fusion. The calorimeter was previously calibrated in temperature and energy with reference materials. Temperature and power scales were calibrated [36-38] at heating rates of 0.04 and $0.17 \mathrm{~K} \mathrm{~s}^{-1}$. The temperature scale was calibrated by the melting temperature of the high-purity reference materials: hexafluorobenzene, tin, and indium [39]. The power scale was calibrated with high-purity indium [39].

Curves of samples hermetically sealed in aluminum pans were recorded in a nitrogen atmosphere. All the pans with the samples were weighed on a Mettler AT21 microbalance with a detection limit of $1 \times 10^{-6} \mathrm{~g}$, before and after the experiments to confirm that no product had volatilized.

After calibration, several runs with high-purity benzoic acid and indium as reference materials [39] were performed under the same conditions as the experimental determinations. The accuracies associated with temperature and enthalpy of fusion measurements were calculated as the percentage deviation of the experimental data with regard to the values given in the literature [39]; in all the cases these were lower than 0.2 and $2.0 \%$ for temperature and enthalpy determinations, respectively [28].

Different scans at heating rates of 0.04 and $0.17 \mathrm{~K} \mathrm{~s}^{-1}$ were performed to determine the possible existence of phase transitions in the samples over the temperature range from $T=260 \mathrm{~K}$ to their respective melting temperatures. A fresh sample was used for each run.

Heat capacities were determined by the "scanning method" following the experimental methodology previously

Table 1 Mean experimental $C_{p, \mathrm{~m}}(\mathrm{cr})$ values

\begin{tabular}{|c|c|c|c|c|c|}
\hline$T / \mathrm{K}$ & $C_{p, \mathrm{~m}}(\mathrm{cr}) / \mathrm{J} \mathrm{K}{ }^{-1} \mathrm{~mol}^{-1}$ & $T / \mathrm{K}$ & $C_{p, \mathrm{~m}}(\mathrm{cr}) / \mathrm{J} \mathrm{K}{ }^{-1} \mathrm{~mol}^{-1}$ & $T / \mathrm{K}$ & $C_{p, \mathrm{~m}}(\mathrm{cr}) / \mathrm{J} \mathrm{K} \mathrm{K}^{-1} \mathrm{~mol}^{-1}$ \\
\hline \multicolumn{6}{|c|}{ L-Cysteine, mol. wt. $\mathrm{C}_{3} \mathrm{H}_{7} \mathrm{NO}_{2} \mathrm{~S}=121.1582$} \\
\hline 263.15 & 129.6 & 320.15 & 149.1 & 390.15 & 171.9 \\
\hline 265.15 & 130.3 & 325.15 & 150.7 & 395.15 & 173.3 \\
\hline 270.15 & 132.0 & 330.15 & 152.5 & 400.15 & 175.3 \\
\hline 273.15 & 133.0 & 335.15 & 154.2 & 405.15 & 177.3 \\
\hline 275.15 & 133.8 & 340.15 & 156.1 & 410.15 & 179.7 \\
\hline 280.15 & 135.1 & 345.15 & 158.3 & 415.15 & 182.2 \\
\hline 285.15 & 136.8 & 350.15 & 159.9 & 420.15 & 182.7 \\
\hline 290.15 & 138.2 & 355.15 & 161.7 & 422.15 & 184.0 \\
\hline 295.15 & 139.7 & 360.15 & 163.3 & & \\
\hline 298.15 & 141.5 & 365.15 & 164.8 & 463.15 & 230.5 \\
\hline 300.15 & 143.2 & 370.15 & 166.5 & 465.15 & 234.6 \\
\hline 305.15 & 145.2 & 375.15 & 167.9 & 470.15 & 247.7 \\
\hline 310.15 & 147.3 & 380.15 & 168.7 & 472.15 & 256.0 \\
\hline 315.15 & 149.1 & 385.15 & 170.1 & & \\
\hline \multicolumn{6}{|c|}{ L-Cystine, mol. wt. $\mathrm{C}_{6} \mathrm{H}_{12} \mathrm{~N}_{2} \mathrm{O}_{4} \mathrm{~S}_{2}=240.3005$} \\
\hline 263.15 & 234.5 & 310.15 & 265.1 & 370.15 & 302.9 \\
\hline 265.15 & 235.9 & 315.15 & 268.7 & 375.15 & 306.1 \\
\hline 270.15 & 239.6 & 320.15 & 271.8 & 380.15 & 310.3 \\
\hline 273.15 & 241.8 & 325.15 & 274.9 & 385.15 & 314.1 \\
\hline 275.15 & 243.3 & 330.15 & 276.6 & 390.15 & 317.8 \\
\hline 280.15 & 246.4 & 335.15 & 281.5 & 395.15 & 321.3 \\
\hline 285.15 & 249.0 & 340.15 & 284.4 & 400.15 & 325.1 \\
\hline 290.15 & 251.8 & 345.15 & 287.5 & 405.15 & 328.7 \\
\hline 295.15 & 254.8 & 350.15 & 289.8 & 410.15 & 332.8 \\
\hline 298.15 & 256.9 & 355.15 & 293.6 & 415.15 & 337.8 \\
\hline 300.15 & 258.2 & 360.15 & 292.1 & 420.15 & 341.9 \\
\hline 305.15 & 261.3 & 365.15 & 299.5 & 422.15 & 344.1 \\
\hline
\end{tabular}


described [40-42] with synthetic sapphire ( $\alpha$-aluminum oxide) as reference material [39-41]. DSC is a commonly accepted method for the quantitative determination of heat capacities and it has been proven as a suitable technique to obtain reliable and accurate values $[43,44]$. To check the experimental method, heat capacity experiments were made with benzoic acid and synthetic sapphire as reference materials [39] in the temperature intervals $T=268-360 \mathrm{~K}$ and $T=268-410 \mathrm{~K}$, respectively [28]. The relative percentage of error of our measurements in comparison with those reported in the literature is less than $2 \%$ [28].

The mass of sapphire used in each run was $0.030345 \mathrm{~g}$. For heat capacity determinations, five to eight fresh samples weighing 7-10 mg were scanned for each solid compound at a heating rate of $0.17 \mathrm{~K} \mathrm{~s}^{-1}$ in the temperature ranges $T=268-473 \mathrm{~K}$ for L-cysteine and $T=268-423 \mathrm{~K}$ for L-cystine. The complete temperature ranges for determination of the heat capacities were divided in intervals of approximately $40 \mathrm{~K}$, overlapping by $5 \mathrm{~K}$ from one interval to another. The estimated uncertainty of the molar heat capacities is less than $2 \%$. The experimental results of each compound were fit to a third-order polynomial in temperature. The relative atomic masses used for the elements were those recommended by the IUPAC Commission in 2005 [45].

\section{Experimental results}

\section{Calorimetric measurements}

For L-cysteine, DSC scans at heating rate $0.17 \mathrm{~K} \mathrm{~s}^{-1}$ in the temperature interval $T=263-517 \mathrm{~K}$ show two enthalpic modifications before fusion in the temperature intervals 446-467 and 468-485 $\mathrm{K}$ with onset temperatures

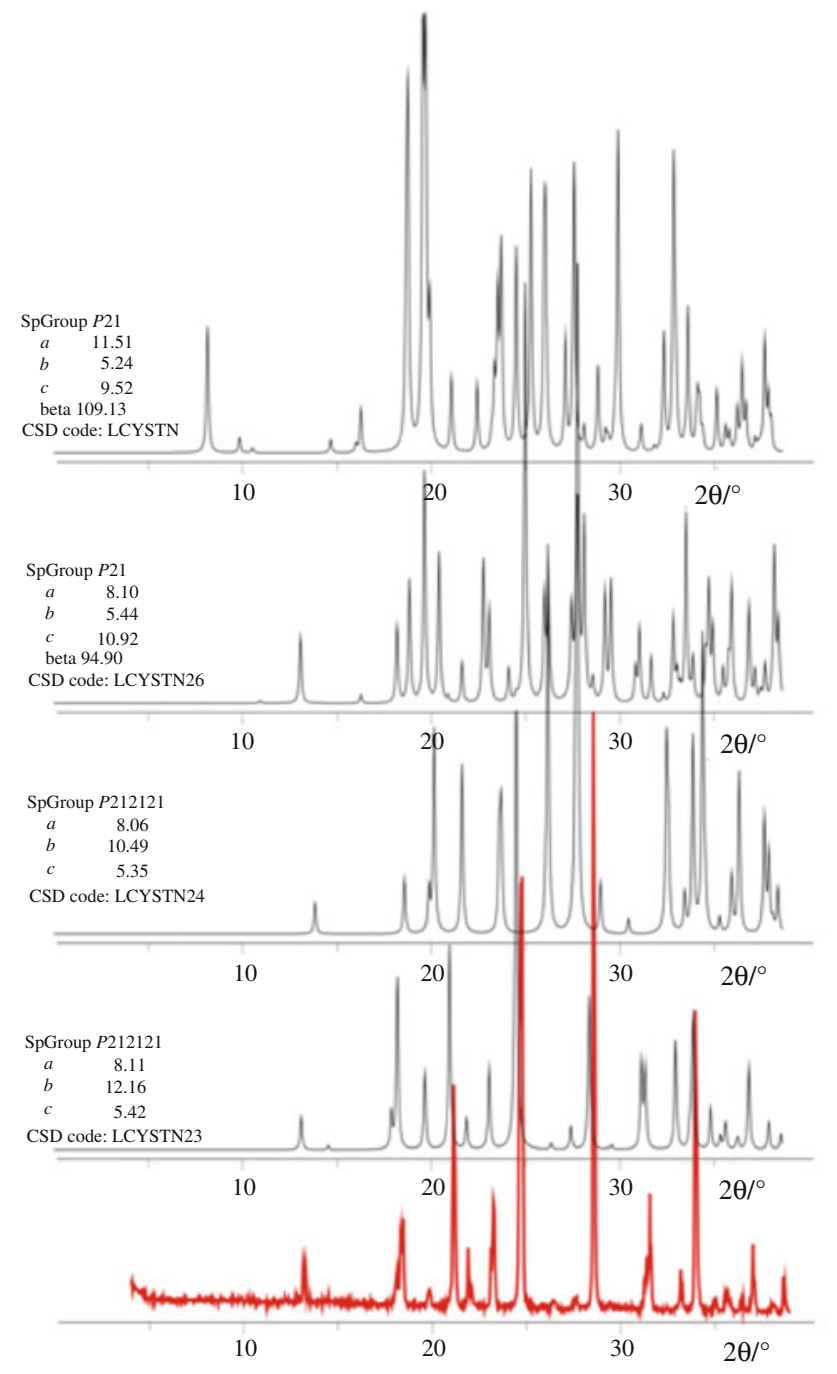

Fig. 4 Simulated powder patterns for the monoclinic (form II and IV) and orthorhombic (form III and I) polymorphs of L-cysteine (in black) and the commercial sample (in red)

Table 2 Coefficients of the fitted curves

\begin{tabular}{|c|c|c|c|c|c|c|}
\hline Compound & $\mathrm{A}^{\mathrm{a}}$ & $\mathrm{B}^{\mathrm{a}}$ & $\mathrm{C}^{\mathrm{a}}$ & $\mathrm{D}^{\mathrm{a}}$ & $r^{2}$ & Range/K \\
\hline L-Cysteine & 1.0954 & 0.0029 & $-4 \times 10^{-7}$ & $-1 \times 10^{-9}$ & 0.999 & $263-422$ \\
\hline L-Cysteine & $-7 \times 10^{-6}$ & 45,601 & -97.901 & 0.0701 & 0.998 & $463-472$ \\
\hline L-Cystine & -241.81 & 3.5785 & -0.0093 & $1 \times 10^{-5}$ & 0.999 & $263-422$ \\
\hline
\end{tabular}

${ }^{a}$ Parameters corresponding to an equation of the type: $C_{p, \mathrm{~m}}=\mathrm{A}+\mathrm{B} T+\mathrm{C} T^{2}+\mathrm{D} T^{3}$

Fig. 3 Molecular structures of orthorhombic form of L-cysteine and the hexagonal form of L-cystine at room temperature and pressure (the dotted line in $\mathrm{L}$-cysteine represents disorder of the $\mathrm{H}$ atom bonded to $\mathrm{S}$ )
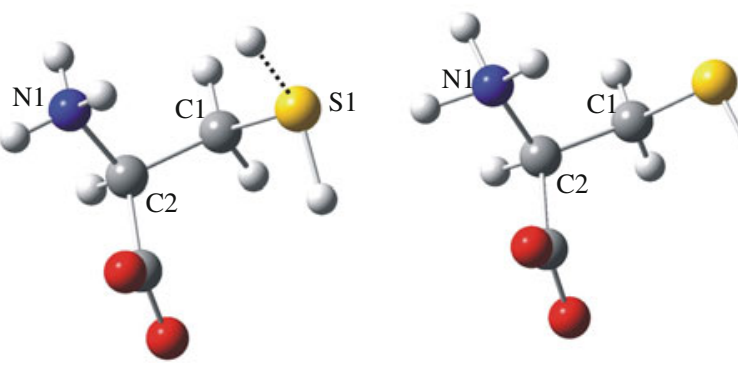
and enthalpies $453.6 \pm 0.4 \mathrm{~K}, 2.6 \pm 0.2 \mathrm{~kJ} \mathrm{~mol}^{-1}$ and $480.2 \pm 0.6 \mathrm{~K}$ and $0.5 \pm 0.1 \mathrm{~kJ} \mathrm{~mol}^{-1}$, respectively. The uncertainties were taken as the standard deviations. Throughout this work temperatures of the enthalpic modifications were taken as onset temperatures, Fig. 2a. This behavior was observed in all the runs performed with fresh samples. For the fusion process a temperature $T_{\text {fus }}=$ $506.0 \pm 0.5 \mathrm{~K}$ was observed. It was not possible to determine the enthalpy of fusion because of the decomposition of the samples immediately after the fusion process. To further study the transformation sequence, a series of DSC experiments were carried out; fresh samples were heated up to $T=485 \mathrm{~K}$ at a heating rate of $0.17 \mathrm{~K} \mathrm{~s}^{-1}$ $\left(10{ }^{\circ} \mathrm{C} \mathrm{min}{ }^{-1}\right.$ ) and after, cooled down to $T=253 \mathrm{~K}$ at $0.17,0.08$, and $0.04 \mathrm{~K} \mathrm{~s}^{-1}$. The enthalpic modifications observed on heating were not observed on cooling and following heating, indicating that the transitions were not reversible.

No solid-solid phase transition was found in L-cystine in the temperature interval $T=263 \mathrm{~K}$ to its melting temperature, Fig. 2b. For the fusion process a temperature $T_{\text {fus }}=503.3 \pm 0.5 \mathrm{~K}$, was observed. It was not possible to determine its enthalpy of fusion because of the decomposition of the samples at the beginning of the fusion process.

\section{Heat capacities}

The mean experimental values of the heat capacity measurements as a function of temperature for the target compounds L-cysteine and L-cystine are given in Table 1.

The coefficients of the fitted third-order equation in temperature for both compounds are collected in Table 2.

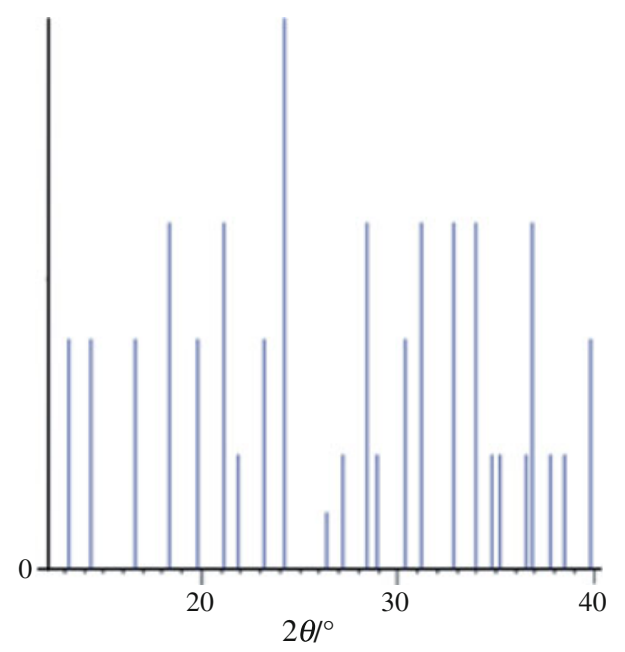

Fig. 5 Experimental stick pattern of the monoclinic form of L-cysteine with unit cell: $13.264,9.657$, and $7.143 \AA$, $\gamma=96.1^{\circ}$ and $P 2$ space group (CSD code LCYSTN03 and PDF code 00-025-1661)
The range studied for each compound is given as the last column in this Table. The errors associated with the use of these correlation equations are less than $2 \mathrm{~J} \mathrm{~K}^{-1} \mathrm{~mol}^{-1}$ for both compounds.

Huffman and Ellis [20] gave for the heat capacity of Lcysteine a value of $c_{p}(\mathrm{cr}, 290 \mathrm{~K})=0.321 \mathrm{cal} \mathrm{g}^{-1} \mathrm{~K}^{-1}$, considering the specific heat data in terms of the $15^{\circ} \mathrm{C}$ cal. Considering 1 cal $\left(15^{\circ} \mathrm{C}\right)=4.1855 \mathrm{~J}$ [46] we obtain for the molar heat capacity the value, $C_{p, \mathrm{~m}}(\mathrm{cr}, 290.0 \mathrm{~K})=$ 158.2 $\mathrm{J} \mathrm{K}^{-1} \mathrm{~mol}^{-1}$. This compares with our value of 138.2 $\mathrm{J} \mathrm{K}^{-1} \mathrm{~mol}^{-1}$.

For L-cystine the value obtained for the heat capacity by Huffman and Ellis [20] was $c_{p}(\mathrm{cr}, 290 \mathrm{~K})=0.261 \mathrm{cal}$ $\left(15^{\circ} \mathrm{C}\right) \mathrm{g}^{-1} \mathrm{~K}^{-1}$ that gives, with the same calculation that previously, $C_{p, \mathrm{~m}}(\mathrm{cr}, 290.0 \mathrm{~K})=262.5 \mathrm{~J} \mathrm{~K}^{-1} \mathrm{~mol}^{-1}$. The value given by Hutchens et al. [21], $C_{p, \mathrm{~m}}(\mathrm{cr}, 290.0 \mathrm{~K})=$ $256.5 \mathrm{~J} \mathrm{~K}^{-1} \mathrm{~mol}^{-1}$, is in good agreement with our value of $251.8 \mathrm{~J} \mathrm{~K}^{-1} \mathrm{~mol}^{-1}$. The difference found is within the uncertainties of the experimental results.

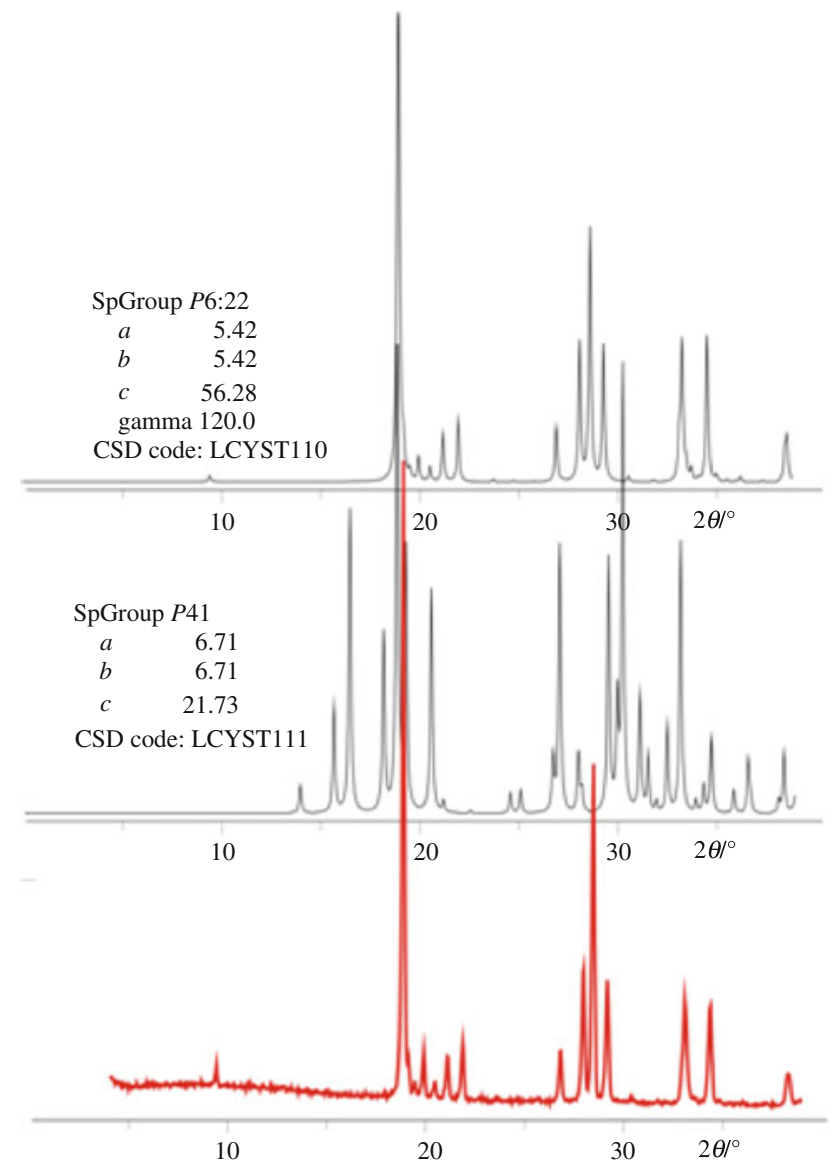

Fig. 6 PXRD patterns for the hexagonal and tetragonal form of L-cystine (in black) and the commercial sample (in red) 
X-ray diffraction analysis

Several polymorphic forms have been previously reported for both compounds according to the Cambridge Crystallographic Database [32]: orthorhombic (forms I and III) and monoclinic (II and IV) for L-cysteine and hexagonal and tetragonal for L-cystine (I-II). The molecular structures of the orthorhombic form of L-cysteine [15] and the hexagonal form of L-cystine [16] at room temperature and pressure are presented in Fig. 3. The labeling of the polymorphs and the atomic numbering are those used in reference [15].

For L-cysteine, the orthorhombic form III at high pressure [15] (LCYSTN24) differs from that of I at ambient temperature and pressure (LCYSTN23) in the conformation of the molecule $\left(\mathrm{N} 1-\mathrm{C} 2-\mathrm{C} 1-\mathrm{S} 1\right.$ ca. $-60^{\circ}$ vs. $\left.+60^{\circ}\right)$. The monoclinic form IV, corresponds to the phase present on decompression of the sample. It is an intermediate structure between the orthorhombic forms where each of the two independent molecules displays one of the conformations mentioned above.

The commercial samples used in this study were characterized by PXRD and the polymorphic form was assigned by comparison with the simulated pattern of the structures retrieved [32]. Representative powder patterns of each polymorph I-IV of L-cysteine, together with the experimental one at room temperature, are illustrated in Fig. 4.

The patterns present structural differences between the polymorphs reflected in the position as well as in the intensities of the peaks. For instance, in the monoclinic form of $\mathrm{L}^{-}$ cysteine LCYSTN [8] (top of Fig. 4) an additional peak at lowest theta values is observed $\left(2 \theta=8.13^{\circ}, d=10.875 \AA\right.$ Á, $\left.I / I_{\max }=32.8 \%\right)$ which is neither observed in the orthorhombic I, III forms (LCYSTN23-24) nor in the monoclinic form IV [15] (LCYSTN26). The pattern also shows differences with respect to the previous experimental powder diffraction study (LCYSTN03 [9] and Powder Diffraction File (PDF) reference code 00-025-1661), Fig. 5), which reported a monoclinic form (unit cell: 13.264, 9.657, and $7.143 \AA ; \gamma=96.1^{\circ}$; and $P 2$ space group). This structure, as far as the CSD [32] is concerned, has never been described by single-crystal X-ray analysis.

Therefore, the polymorphic forms can be readily distinguished by their powder X-ray patterns, even those that correspond to conformational changes maintaining the supramolecular structure as in polymorphs I (LCYSTN23) and III (LCYSTYN24), Fig. 4. The commercial sample of L-cysteine can be assigned to the orthorhombic phase I (LCYSTN and LCYSTN23).

Simulated powder patterns of the hexagonal and tetragonal polymorphs of L-cystine together with the experimental one at room temperatures are illustrated in Fig. 6. The commercial sample, at room temperature, is consistent with the simulated hexagonal form of L-cystine.

For L-cysteine taken into account the solid-solid phase transition detected by the thermal analysis (ca. 464 and $480 \mathrm{~K}$ in Fig. 2a), a PXRD analysis at variable temperature was carried out (Fig. 7).

Initially, the pattern was recorded at room temperature. The sample were then heated $\left(0.17 \mathrm{~K} \mathrm{~s}^{-1}\right.$ rate $)$ to temperatures: $T=423,443,463$, and $488 \mathrm{~K}$ and the PXRD recorded. At $T=298$ and $423 \mathrm{~K}$ the patterns are essentially the same. However, when increasing the temperature, a gradual disappearance of various crystalline peaks (ca. $2 \theta=28.6^{\circ}$ and $34.2^{\circ}$ with relative intensities of 100 and $51.5 \%$ ) and the appearance of new ones (c.a. $2 \theta=7.9^{\circ}$, $19.9^{\circ}$ and intensities 26.9 and $36.4 \%$ at $463 \mathrm{~K}$, Table 3 and Fig. 7) indicate that the sample has transformed to a new phase and that the pattern at $443 \mathrm{~K}$ could correspond to intermediate phases or to a mixture of two phases, room temperature and the high temperature phase. The pattern at $T=488 \mathrm{~K}$, just before melting, only shows a very few sharp peaks suggesting a nearly amorphous phase.

The powder pattern as recorded at $T=463 \mathrm{~K}$ shows that the high temperature modification could be only indexed in the triclinic system. The initial unit cell dimensions $\left(a_{1}=5.627 \AA\right.$ А $b_{1}=10.099 \AA, c_{1}=16.648 \AA$, $\alpha_{1}=$
Fig. 7 Variable temperature PXRD patterns heating at a rate of $0.17 \mathrm{~K} \mathrm{~s}^{-1}$ for L-cysteine: $298 \mathrm{~K}$ (red), $423 \mathrm{~K}$ (blue), $443 \mathrm{~K}$ (yellow), $463 \mathrm{~K}$ (green) and $488 \mathrm{~K}$ (brown)

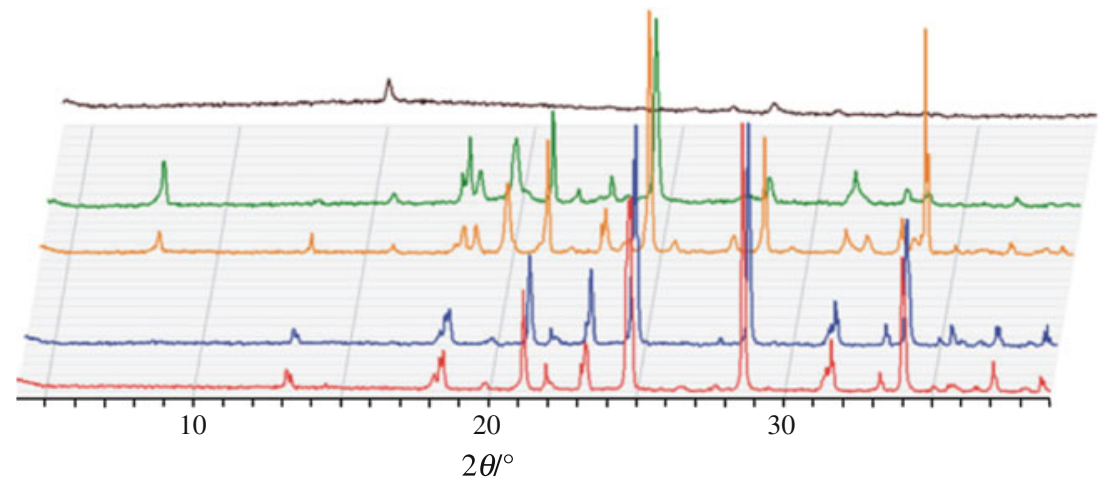


$138.1^{\circ}, \beta_{1}=89.6^{\circ}$, and $\left.\gamma_{1}=93.0^{\circ}\right)$ as determined with TREOR90 [47] were further reduced [34] $(a=\mathbf{b 1}+\mathbf{c 1}$, $b=\mathbf{a} \mathbf{1}, c=\mathbf{b} \mathbf{1}$ in vectorial notation) and finally refined with XPowder [35]. The results of the refinement together with the observed positions, spacing and relative intensities are listed in Table 3. The resulting transformed and refined cell

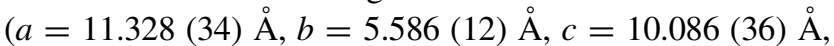
$\alpha=92.6(3)^{\circ}, \beta=101.9(3)^{\circ}$ and $\gamma=91.9(3)^{\circ}$ with $\left.Z=4\right)$ is similar to that of the monoclinic form II (LCYSTN in Fig. 4). The indexed cell means that the transformation occurs with a loss of symmetry (four independent molecules in the cell instead of two and an increasing of the unit cell volume $\left(V=623(4)\right.$ vs. 534.8(2) $\AA^{3}$ ) as could be expected when increasing the temperature. The lack of an appropriate cell [47] for the pattern at $T=443 \mathrm{~K}$ could be also an indication that the patterns could correspond to intermediate phases or to a mixture of both room and highest temperature phases.

Table 3 Observed and calculated PXRD pattern at $463 \mathrm{~K}$ (Fig. 7): observed $2 \theta$ angle $\left(^{\circ}\right)$ and $d$-spacing $(\AA)$, calculated $d$-spacing $(\AA)$, relative intensities $(\%)$ and Miller indices for the 65 reflections after refinement $(a=11.328$ (34) $\AA, \quad b=5.586 \quad$ (12) $\AA, c=10.086$ (36) $\AA, \alpha=92.6(3)^{\circ}, \beta=101.9(3)^{\circ}$ and $\gamma=91.9(3)^{\circ}$ cell parameters, according factor for $Q(\mathrm{o}, \mathrm{c})=0.0022$ and weighted standard deviation $=0.0022$

\begin{tabular}{|c|c|c|c|c|}
\hline $2 \theta /^{\circ}$ & $d$-Obs/Å & $d$-Calc/Å & $I / \mathrm{I}_{\mathrm{o}} / \%$ & $h k l$ \\
\hline 7.94 & 11.129 & 11.070 & 26.9 & $100,-100$ \\
\hline 15.76 & 5.619 & 5.535 & 11.5 & 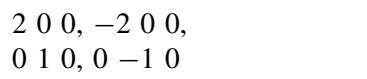 \\
\hline 18.30 & 4.844 & 4.927 & 40.2 & 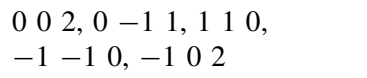 \\
\hline 18.67 & 4.750 & 4.645 & 23.1 & $-1-11,011,201$ \\
\hline 19.87 & 4.465 & 4.428 & 36.4 & $1-11$ \\
\hline 21.14 & 4.199 & 4.188 & 53.2 & $102,111,-201$ \\
\hline 21.98 & 4.041 & 4.022 & 12.1 & $2-10,-210$ \\
\hline 23.11 & 3.845 & 3.881 & 20.5 & $\begin{array}{l}-2 \quad 1 \quad 1,2 \quad 10,-2-10 \\
-2-11,0-12\end{array}$ \\
\hline 24.58 & 3.618 & 3.690 & 80.4 & $300,-300,-112$ \\
\hline 24.62 & 3.614 & 3.597 & 100.0 & $012,2-11$ \\
\hline 28.46 & 3.134 & 3.145 & 19.4 & 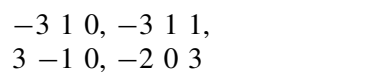 \\
\hline 31.37 & 2.850 & 2.876 & 22.8 & 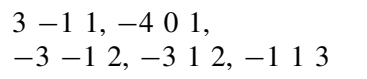 \\
\hline 33.14 & 2.701 & 2.733 & 12.8 & 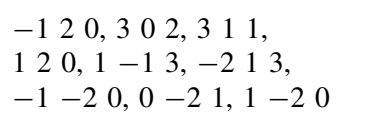 \\
\hline 33.84 & 2.647 & 2.650 & 12.2 & $\begin{array}{l}-1-21,-402,-121, \\
021,1-21\end{array}$ \\
\hline 36.82 & 2.439 & 2.434 & 9.5 & $\begin{array}{l}410,220,2-13,2-21 \\
-4-10,-412,-313, \\
-2-2 \quad 0,-2-21, \\
-204,-1-22,004\end{array}$ \\
\hline
\end{tabular}

Comparison of the results by DSC and variable temperature PXRD analysis in L-cysteine

The main discrepancy between the preliminary results with both techniques concerns the number of solid-solid transformations observed at temperatures higher than $T=423 \mathrm{~K}$; in the DSC, two enthalpic modifications were observed before fusion (ca. 464 and 480 K, Fig. 2a) and only one by X-ray with a gradual transformation of $T=423-463 \mathrm{~K}$ (powder patterns recorded at $T=423 \mathrm{~K}$ is essentially the same of that at $T=298 \mathrm{~K}$, Fig. 7).
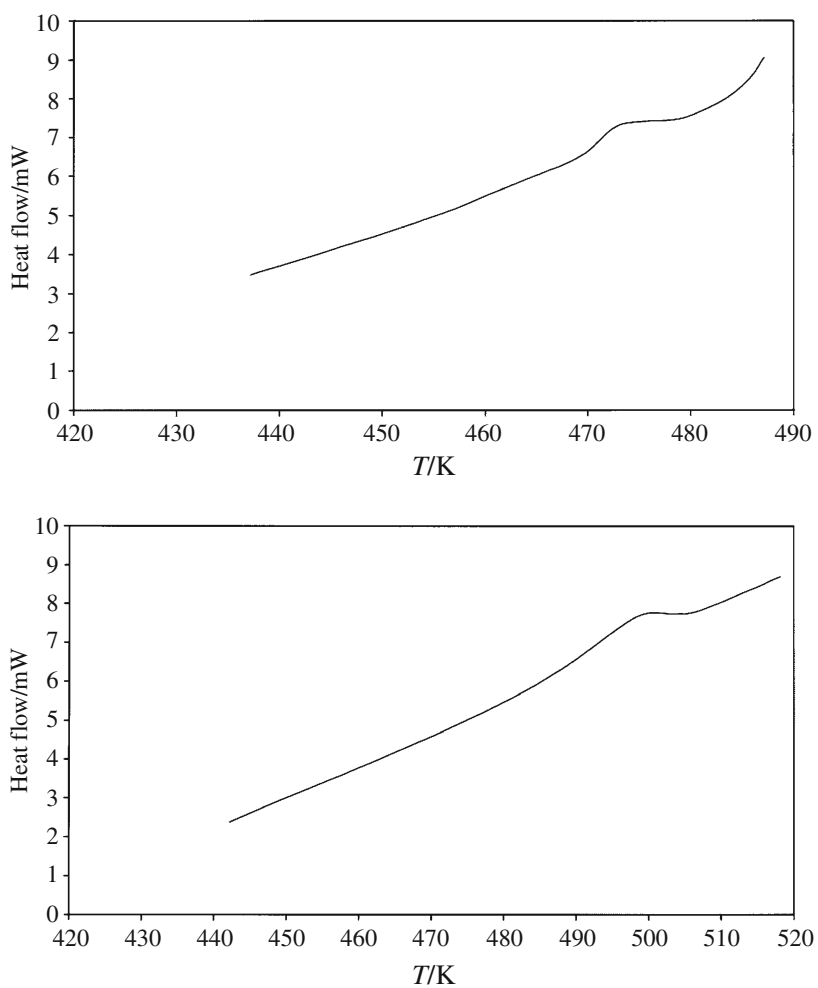

Fig. 8 DSC scan after heating of the sample of L-cysteine at $T=433 \mathrm{~K}$ during $2 \mathrm{~h}$ (top) and $20 \mathrm{~h}$ (bottom)

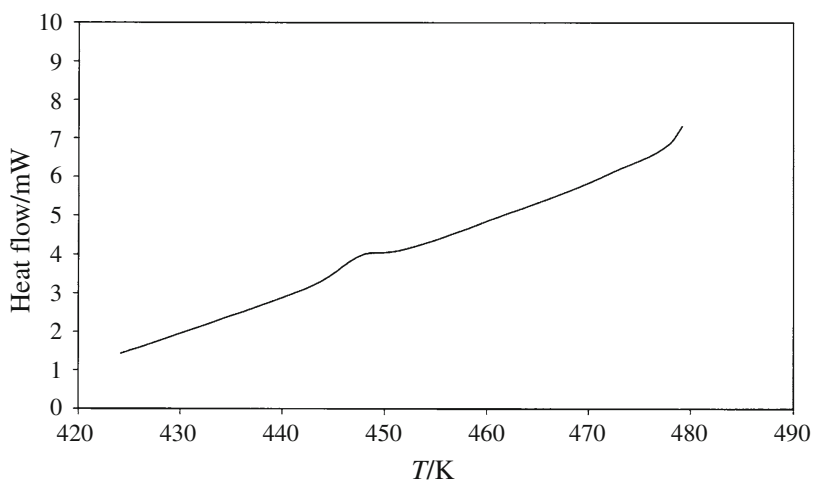

Fig. 9 Behavior of a sample of L-cysteine recording at a heating rate of $0.04 \mathrm{~K} \mathrm{~s}^{-1}$ 
In an attempt to clarify the sequence of transformation steps, isothermal heat treatments were carried out by heating the samples in the DSC calorimeter at $T=433 \mathrm{~K}$ for different times $(1,2,3$, and $20 \mathrm{~h}$ ), followed by a scan up to the fusion temperature at a heating rate of $0.17 \mathrm{~K} \mathrm{~s}^{-1}$. The results obtained at times of $1,2,3 \mathrm{~h}$ were similar with only one enthalpic modification observed before fusion. As an example, Fig. 8 shows the results obtained in the experiment at $2 \mathrm{~h}$. The enthalpic modification is produced in the temperature interval of $T=467.9-478.4 \mathrm{~K}$ with $T_{\text {onset }}=469.8 \mathrm{~K}, T_{\text {peak }}=473.0 \mathrm{~K}$, and $\Delta_{\text {trans }} H=$ $3.2 \mathrm{~J} \mathrm{~g}^{-1}$. The fusion process begins at $T=481 \mathrm{~K}$.

The results obtained when the sample is maintained for $20 \mathrm{~h}$ at $T=433 \mathrm{~K}$ (Fig. 8) shows that the enthalpic modification before fusion is lost and a broad peak in the temperature interval $T=474.3-508.2 \mathrm{~K}$ is present. This peak corresponds to the fusion of the sample with $T_{\text {onset }}=485.3 \mathrm{~K}$ and $T_{\text {peak }}=498.2 \mathrm{~K}$. In order to study the behavior of L-cysteine at different heating rates, experiments at heating rates 0.017 , 0.04 and $0.08 \mathrm{~K} \mathrm{~s}^{-1}$ were carried out. At heating rates of 0.017 and $0.04 \mathrm{~K} \mathrm{~s}^{-1}$, only one enthalpic modification is present. In Fig. 9, the result obtained at a heating rate of $0.04 \mathrm{~K} \mathrm{~s}^{-1}$ is given. The transition is produced at the temperature interval $T=442.2-450.8 \mathrm{~K}$ con $T_{\text {onset }}=444.2 \mathrm{~K}$, $T_{\text {peak }}=445.7 \mathrm{~K}$, and $\Delta_{\text {trans }} H=9.1 \mathrm{~J} \mathrm{~g}^{-1}$. The fusion process at this heating rate begins at $474.2 \mathrm{~K}$.
According to these results, in order to gain further insight into the thermal behavior and to explore the evolution of the transformation of the sample, new PXRD experiments were undertaken as a function of the heating rate as well as time of the initial heating.

First of all, the powder patterns were recorded at lower heating rates of $0.017,0.03$, and $0.08 \mathrm{~K} \mathrm{~s}^{-1}$ every $5 \mathrm{~K}$. Similar features can be observed in all of them and Fig. 10 illustrates the PXRD pattern for a heating rate of $0.03 \mathrm{~K} \mathrm{~s}^{-1}$. The sample shows a slow evolution up to $T=473 \mathrm{~K}$ as previously observed (Fig. 7) and even at $468 \mathrm{~K}$ (pattern in light blue in Fig. 10) a triclinic cell could be indexed [47] and reduced [34] $(a=11.593 \AA$ A $b=5.858 \AA, c=9.856 \AA$, $\alpha=92.6^{\circ}, \beta=100.0(3)^{\circ}$, and $\gamma=101.6^{\circ}, V=644.1 \AA^{3}$ with $Z=4$ ). The patterns at $T=473$ and $488 \mathrm{~K}$ show broader and fewer sharp peaks suggesting an almost amorphous phase. These results are in agreement with those obtained by DSC where the transition occurs in the $T=442-451 \mathrm{~K}$ range and the phase transition begins at $T=474 \mathrm{~K}$. The difference between the temperatures determined by DSC and those at which the X-ray pattern is recorded may be due to the time required for the X-ray measurements (20 min).

Furthermore, the sample was heated for longer times (2 and $20 \mathrm{~h}$ ) at $T=433 \mathrm{~K}$ (before the first transformation in Fig. 7) to analyze the transformation of the sample as a
Fig. 10 Variable temperature PXRD patterns heating the sample of L-cysteine at $0.03 \mathrm{~K} \mathrm{~s}^{-1}$ : $298 \mathrm{~K}$ (red), $423 \mathrm{~K}$ (dark blue), $433 \mathrm{~K}$ (dark pink), $443 \mathrm{~K}$ (yellow), $453 \mathrm{~K}$ (green), $463 \mathrm{~K}$ (black), $468 \mathrm{~K}$ (blue), $473 \mathrm{~K}$ (pink) and $483 \mathrm{~K}$ (brown)

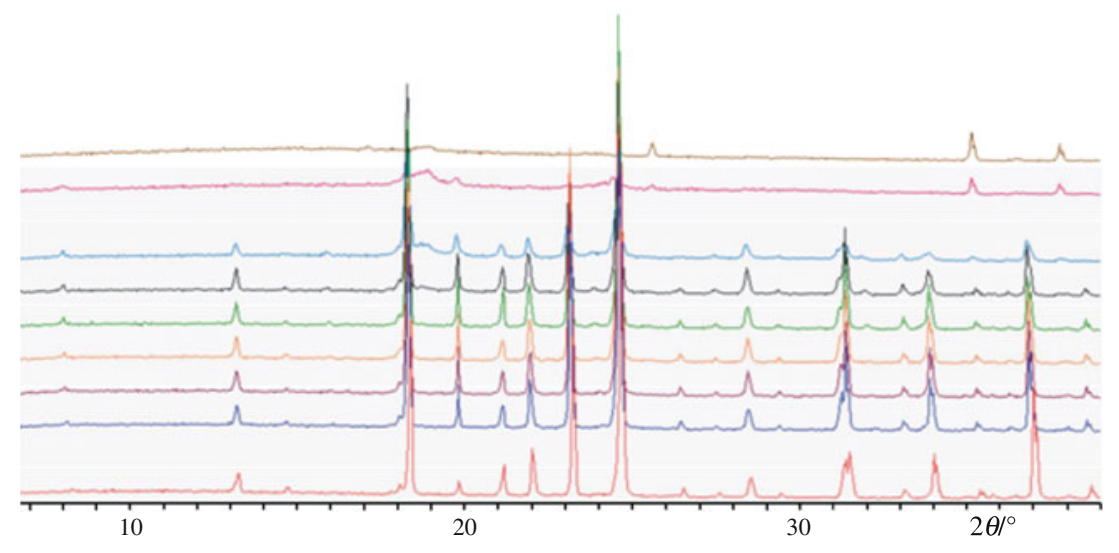

Fig. 11 Variable-temperature PXRD patterns heating at $T=433 \mathrm{~K}$ during $20 \mathrm{~h}$, only the initial and those recorded after 2, 4, 8, 12, 16 and $20 \mathrm{~h}$ have been plotted. After that, the sample was heated at $443 \mathrm{~K}$ (yellow), $453 \mathrm{~K}$ (green), $463 \mathrm{~K}$ (black), $473 \mathrm{~K}$ (pink) and $483 \mathrm{~K}$ (brown)

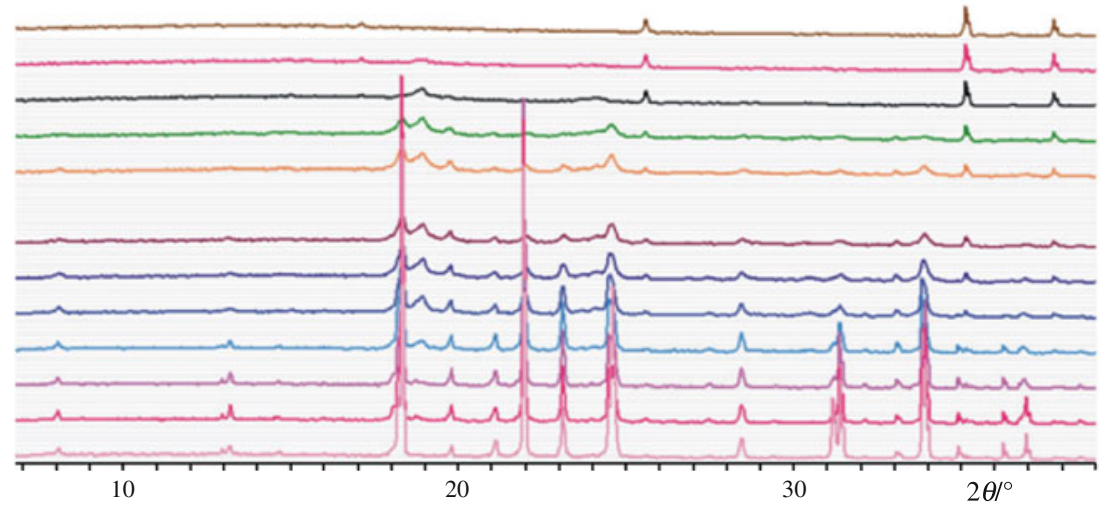


function of the time of heating. Figure 11 illustrates the transformation of the sample when heating at $T=433 \mathrm{~K}$ during $20 \mathrm{~h}$. The diffractograms were recorded every hour during this period of time although, due to the evolution of the sample, only some of them have been represented in Fig. 11. Further, the temperature was increased up to $483 \mathrm{~K}$. During heating at $433 \mathrm{~K}$ a gradual transformation of the sharp to broad peaks can be observed accompanied by a disappearance of peaks and the pattern resembles that observed at $473 \mathrm{~K}$ (Fig. 10) close to melting. In the DSC experiments (see above) no transition was detected and only the fusion peak was observed.

\section{Conclusions}

From the combination of the thermal and powder X-ray powder analysis the following conclusion can be drawn:

The X-ray powder analysis identifies the commercial samples as the orthorhombic and hexagonal polymorphs of L-cysteine and L-cystine, respectively, as reported from the single-crystal analysis. It also gave evidence for solid-solid phase transition close to the melting point only in the Lcysteine sample in agreement with the DSC results. The thermal behavior of the sample depends on the heating rate as well as the time of heating with gradual change of the sample that could correspond to the formation of a mixture of phases. This solid-solid transition is not reversible in the temperature interval $253-485 \mathrm{~K}$. The highest temperature modification observed at 463-468 $\mathrm{K}$ (depending on the heating rate) is triclinic ( $P 1$ due to the chirality of the molecule) with a similar cell to that of the orthorhombic and monoclinic form at ambient conditions although with four independent molecules instead of one and two, respectively, suggesting a loss of symmetry with increasing temperature.

Acknowledgements The authors thank the support of the Spanish Ministerio de Ciencia e Innovación under Projects CTQ2007-60895/ BQU, CTQ2010-16402 and HP2007-0123. The authors also thank Dr. Fernando Conde López of the C.A.I. Difracción de Rayos X (Farmacia) Universidad Complutense de Madrid, for recording the $\mathrm{X}$-ray powder diffraction patterns.

Open Access This article is distributed under the terms of the Creative Commons Attribution Noncommercial License which permits any noncommercial use, distribution, and reproduction in any medium, provided the original author(s) and source are credited.

\section{References}

1. Li HM, Thomas GJ. Cysteine conformation and sulfhydryl interactions in proteins and viruses. 1. Correlation of the Raman $\mathrm{S}-\mathrm{H}$ band with hydrogen bonding and intramolecular geometry in model compounds. J Am Chem Soc. 1991;113:456-62.
2. Lu XF, Galkin A, Herzberg O, Dunaway-Mariano D. Arginine deiminase uses an active-site cysteine in nucleophilic catalysis of L-arginine hydrolysis. J Am Chem Soc. 2004;126:5374-5.

3. Kadokura H, Katzen F, Beckwith J. Protein disulfide bond formation if prokaryotes. Annu Rev Biochem. 2003;72:111-35.

4. Ellgaard L, Reddock LW. The human protein disulphide isomerase family: substrate interactions and functional properties. EMBO Rep. 2005;1:28-32.

5. Singh R, Whitesides GM. Thiol-disulfide interchange. In: Patai S, Rappoport Z, editors. Supplement 5: the chemistry of sulfurcontaining functional groups. London: Wiley; 1993. p. 633-58.

6. Boldyreva EV. Crystalline amino acids-a link between chemistry, material sciences and biology. In: Boeyens JCA, Ogilvie JF, editors. Models, mysteries, and magic of molecules. Berlin, Heidelberg, New York: Springer-Verlag; 2007. p. 169-94.

7. Ringe D, Petsko GA. The 'glass transition' in protein dynamics: what it is, why it occurs, and how to exploit it. Biophys Chem. 2003;105:667-80.

8. Harding MM, Long HA. The crystal and molecular structure of L-cysteine. Acta Crystallogr B. 1968;24:1096-102.

9. Khawas B. X-ray study of L-arginine $\mathrm{HCl}$, L-cysteine, DL-lysine and DL-phenylalaline. Acta Crystallogr B. 1971;27:1517-20.

10. Kerr KA, Ashmore JP. Structure and conformation of orthorhombic L-cysteine. Acta Crystallogr B. 1973;29:2124-7.

11. Kerr KA, Ashmore JP, Koetzle TF. A neutron diffraction study if L-cysteine. Acta Crystallogr B. 1975;31:2022-6.

12. Görbitz CH, Dalhus B. L-Cysteine, monoclinic form, redetermination at $120 \mathrm{~K}$. Acta Crystallogr B. 1996;52:1756-9.

13. Moggach SA, Clark SJ, Parsons S. L-Cysteine I at $30 \mathrm{~K}$. Acta Crystallogr E. 2005;61:o2739-42.

14. Kolesov BA, Minkov VS, Boldyreva EV, Drebushchak TN. Phase transitions in the crystal of $\mathrm{L}$ - and $\mathrm{D}, \mathrm{L}$-cysteine on cooling: intermolecular hydrogen bonds distortions in the side-chain motions of thiol groups. 1. L-cysteine. J Phys Chem B. 2008;112:12827-39.

15. Moggach SA, Allan DR, Clark SJ, Gutmann MJ, Parsons S, Pulham CR, Sawyer L. High pressure polymorphism in L-cysteine: the crystal structures of L-cysteine III and L-cysteine IV. Acta Crystallogr B. 2006;62:296-309.

16. Oughton BM, Harrison PM. The crystal structure of hexagonal L-cystine. Acta Crystallogr. 1959;12:396-404.

17. Chaney MO, Steinrauf LK. The crystal and molecular structure of tetragonal L-cystine. Acta Crystallogr B. 1974;30:711-6.

18. Dahaoui S, Pichon-Pesme V, Howard JAK, Lecomte C. CCD charge density study on crystal with large unit cell parameters: the case of hexagonal L-cystine. J Phys Chem A. 1999;106:6240-50.

19. Moggach SA, Allan DR, Parsons S, Sawyer L, Warren JEJ. The effect of pressure on the crystal structure of hexagonal L-cystine. Synchrotron Radiat. 2005;12:598-607.

20. Huffman HM, Ellis EL. Thermal data III. The heat capacities, entropies and energies of four organic compounds containing sulphur. J Am Chem Soc. 1935;57:46-8.

21. Hutchens JO, Cole AG, Stout JW. Heat capacities and entropies of L-cystine and L-methionine. The transition of L-methionine near 305.5 K. J Biol Chem. 1964;239:591-5.

22. Paukov IE, Kovalevskaya YA, Drebushchak VA, Drebushchak $\mathrm{TN}$, Bildyreva EV. An extended phase transition in crystalline L-cysteine near 70 K. J Phys Chem B. 2007;111:9186-8.

23. Roux MV, Dávalos JZ, Jiménez P. Effect of pressure on the polymorphic forms of famotidine. Thermochim Acta. 2002;394:19-24.

24. Jiménez P, Roux MV, Dávalos JZ, Temprado M. Heat capacities and enthalpies of transitions of three nitrobenzonitriles. Thermochim Acta. 2002;394:25-9.

25. Roux MV, Temprado M, Jiménez P, Guzmán-Mejía R, Juaristi E, Chickos JS. Heat capacities of thiane sulfones and thiane sulfoxide. Refining of $\mathrm{Cp}$ group values for organosulfur compounds and their oxides. Thermochim Acta. 2003;406:9-16. 
26. Roux MV, Temprado M, Jiménez P, Dávalos JZ, Foces-Foces C, García MV, Redondo MI. Thermophysical, crystalline and infrared studies of the 2- and 3-thiophenecarboxylic acids. Thermochim Acta. 2003;404:235-44.

27. Roux MV, Temprado M, Jiménez P, Foces-Foces C, García MV, Redondo MI. 2- and 3-Furancarboxylic acids: a comparative study using calorimetry, IR spectroscopy and X-ray crystallography. Thermochim Acta. 2004;420:59-66.

28. Temprado M, Roux MV, Jiménez P, Guzmán-Mejía R, Juaristi E, Chickos JS. Thermophysical properties of sulfur heterocycles: thiane and thiophene derivatives. Thermochim Acta. 2006;441: $20-6$.

29. Temprado M, Roux MV, Jiménez P, Parameswar RAR, Demchenko AD, Chickos JS, Liebman JF. Thermophysical properties in medium temperature range of several thio and dithiocarbamates. J Therm Anal Calorim. 2008;91:471-5.

30. Temprado M, Roux MV, Chickos JS. Some thermophysical properties of several solid aldehydes. J Therm Anal Calorim. 2008;91:257-62.

31. Roux MV, Foces-Foces C, Notario R, Ribeiro da Silva MAV, Ribeiro da Silva MDMC, Santos AFLOM. Experimental and computational thermochemistry study of sulfur containing amino acids: L-cysteine, L-cystine and L-cysteine radicals. S-S, S-H and C-S bond dissociation enthalpies. J Phys Chem B. 2010;114: 10530-40.

32. Allen FH. The Cambridge Structural Database: a quarter of a million crystal structures and rising. Acta Crystallogr. 2002;58:380-8.

33. Spek AL. Single-crystal structure validation with the program PLATON. J Appl Crystallogr. 2003;36:7-13.

34. Farrugia LJ. WinGX suite for small-molecule single-crystal crystallography. J Appl Crystallogr. 1999;32:837-8.

35. Martin JD. Using XPowder: a software package for powder X-ray diffraction analysis. 2004. www.xpowder.com D.L. GR 1001/04. ISBN 84-609-1497-6, 105 p, Spain.

36. Gmelin E, Sarge SM. Temperature, heat and heat flow rate calibration of differential scanning calorimeters. Thermochim Acta. 2000;347:9-13.
37. Sarge SM, Gmelin E, Höhne GWH, Cammenga HK, Hemminger $\mathrm{W}$, Eysel W. The caloric calibration of scanning calorimeters. Thermochim Acta. 1994;247:129-68.

38. GEFTA (Gesellschaft für Thermische Analyse, Germany), Gmelin E, Sarge SM. Calibration of differential scanning calorimeters. Pure Appl Chem. 1995;67:1789-1995.

39. Sabbah R, Xu-Wu A, Chickos JS, Planas-Leitão ML, Roux MV, Torres LA. Reference materials for calorimetry and differential thermal analysis. Thermochim Acta. 1999;331:93-204.

40. Mraw SC, Naas DF. The measurement of accurate heat capacities by differential scanning calorimetry. Comparison of d.s.c. results on pyrite $(100$ to $800 \mathrm{k}$ ) with literature values from precision adiabatic calorimetry. J Chem Thermodyn. 1979;11:567-84.

41. $\mathrm{O}^{\prime}$ Neill MJ. Measurement of specific heat functions by differential scanning calorimetry. Anal Chem. 1996;38:1331-6.

42. Callanan JE, Sullivan SA. Development of standard operating procedures for differential scanning calorimeters. Rev Sci Instrum. 1986;57:2584-92.

43. Pak J, Qiu W, Pyda M, Nowak-Pyda E, Wunderlich B. Can one measure precise heat capacities with dsc or tmdsc? A study of the baseline and heat-flow rate correction. J Therm Anal Calorim. 2005;82:565-74.

44. Rudtsch S. Uncertainty of heat capacity measurements with differential scanning calorimeters. Thermochim Acta. 2002;382: $17-25$.

45. Wieser ME. Atomic weights of the elements 2005 (IUPAC technical report). Pure Appl Chem. 2006;78:2051-66.

46. Cox JD, Pilcher G. Thermochemistry of organic and organometallic compounds, Chapter 1. London: Academic Press; 1970. p. 6.

47. Werner PE, Eriksson L, Westdahl M. TREOR90, a semiexhaustive trial-and-error powder indexing program for all symmetries. J Appl Crystallogr. 1985;18:367-70. 